\title{
Sensitization Profiles of Timothy Grass Pollen in Northern China
}

\author{
Yingyang $\mathrm{Xu}\left(\mathbb{I}^{1-3}\right.$ \\ Kai Guan ${ }^{1-3}$ \\ Li Sha ${ }^{4}$ \\ Jinghong Zhang ${ }^{5}$ \\ Yongliang $\mathrm{Niu}^{6}$ \\ Jia $\mathrm{Yin}^{1-3}$ \\ Lianglu Wang ${ }^{1-3}$
}

'Department of Allergy, Peking Union Medical College Hospital, Chinese Academy of Medical Sciences \& Peking Union Medical College, Beijing, 100730, People's Republic of China; ${ }^{2}$ Beijing Key Laboratory of Precision Medicine for Diagnosis and Treatment on Allergic Diseases, Beijing, 100730, People's Republic of China; ${ }^{3}$ National Clinical Research Center for Dermatologic and Immunologic Diseases, Beijing, 100730, People's Republic of China; ${ }^{4}$ Department of Allergy, Capital Institute of Pediatrics, Beijing, I00020, People's Republic of China; ${ }^{5}$ Department of Allergy, The No.I People's Hospital of Shizuishan, Shizuishan, 753000, Ningxia Hui Autonomous Region, People's Republic of China; ' $D$ Department of Respiratory and Critical Care Medicine, Shenmu Hospital, Shenmu, 719300, Shanxi, People's Republic of China

Correspondence: Kai Guan Department of Allergy, Peking Union Medical College Hospital, \#I Shuaifuyuan, Wangfujing, Beijing, 100730, People's Republic of China

Tel +86 10 69151605

Fax +861069156346

Emaildr_guankai@I26.com
Purpose: Grass pollen is an important cause of IgE-mediated allergy in countries worldwide, especially within Europe. However, there has been no research on grass pollen allergy in northern China. We aimed to determine the status of grass pollen allergy and the sensitization patterns to Phleum pratense ( $P$. pratense) in northern China.

Patients and Methods: Pollen data were collected for three geographic areas (Beijing, Shenmu, Shizuishan) in northern China. The study enrolled 101 patients (62 men; age range, 1-64 years; median age, 10 years) who had allergic rhinoconjunctivitis and/or asthma during the grass pollen season and positive skin prick test results positive to $P$. pratense. Serum-specific IgE (sIgE) against Phl p 1, Phl p 2, Phl p 5, Phl p 6, Phl p 7, Phl p 12 was measured by ImmunoCAP. Results: The pollen season of $P$. pratense was from June to September in Beijing, May to September in Shenmu and July to August in Shizuishan. P. pratense pollen accounted for $2-$ $3 \%$ of the annual pollen index of total pollen counts. Among 101 patients with positive skin prick test results to $P$. pratense, $72 \%$ had detectable sIgE to $P$. pratense. $\mathrm{Phl} \mathrm{p} 12$ was the most frequently recognized component (45\%), followed by Phl p 1 (22\%), Phl p 5 (14\%), Phl p $6(8 \%)$ and $\mathrm{Phl} \mathrm{p} 7$ (3\%). No patients had sIgE to $\mathrm{Phl}$ p 2. Ten sensitization patterns to the six components were observed. High rate of SIgE to Phl p 12 was positively correlated with co-sensitization to weed or tree pollen.

Conclusion: Considering the pollen concentration, $P$. pratense was a minor pollen allergen in northern China and its pollen season overlapped with that of weed pollen. IgE sensitization to $P$. pratense was likely to be induced by cross-reactivity between grass pollen allergy and weed/tree pollen allergy.

Keywords: allergic rhinitis, allergen components, grass pollen allergy, Phleum pratense, Phl p 12

\section{Introduction}

The term "grass" refers to plants belonging to the Poaceae family. However, "grass" is often confused with "weed" in China. Even in some literature reports, grass was misrepresented as mugwort, Japanese hop or other weed species. Poaceae pollen is the leading cause of pollen allergy in countries worldwide, especially in Europe and north America. ${ }^{1}$ During the Poaceae pollen season, generally late spring and early summer in the Northern Hemisphere, grasses produce large quantities of pollen and may cause allergic rhinoconjunctivitis (ARC) or asthma in susceptible individuals. It was estimated that $15 \%$ of the general population in the United States and $20 \%$ of the general population in Europe suffer from grass pollen allergy. ${ }^{2,3}$

Three Poaceae subfamilies: Pooideae, Chloridoideae and Panicoideae, account for $>95 \%$ of allergy-relevant grass species. ${ }^{4}$ The allergenicity of different species in the Poaceae family shows extensive cross-reactivity. ${ }^{5,6}$ For example, determination 
of IgE to Phleum pratense (P. pratense, timothy grass), the most common pollen for grass allergy, produced similar results in the majority of species in the Poaceae family. ${ }^{7}$ To date, nine allergens from $P$. pratense have been officially recorded by the IUIS Allergen Nomenclature SubCommittee. Among them, the combination of Phl p 1 and $\mathrm{Phl} \mathrm{p} 5$ is a unique marker for timothy grass sensitization, while Phl p 7 (polcalcin) and Phl p 12 (profilin) have broad cross-reactivity. Phl p 1 shows $80 \%$ homology to group 1 allergens from other grasses ${ }^{8}$ and shares $\operatorname{IgE}$ epitopes with eight grass pollens. ${ }^{9} \mathrm{Phl}$ p 5 shows high cross-reactivity with other group 5 allergens in the family. ${ }^{4,10}$ Therefore, we chose $P$. pratense as a representative allergy relevant grass pollen.

Data on sensitization profiles to grass pollen are available in Europe and the United States but are relatively infrequent elsewhere. Only a few studies on grass pollen allergy in Asia and Africa have been published. ${ }^{11-13}$

China has a vast territory that crosses approximately 50 latitudes. Thus, the vegetation from the north to the south of China shows large diversity. ${ }^{14,15}$ In southern China, taking Zhongshan city in Guangzhou province as an example, Poaceae is the most abundant pollen throughout the year, with a peak season in November and accounts for $27 \%$ of the annual pollen quantity. ${ }^{16}$ Following Poaceae, Pinus, Taxodiaceae, Cupressaceae, Broussonetia and Casuarinaceae are the other common pollen types with peak seasons in February and March. ${ }^{16}$ In northern China, trees and weeds produce the major pollen types, and format two main allergenic pollen seasons. ${ }^{17,18}$ One season occurs in spring and is caused by tree pollens including Salix caprea, Sabina chinensis, Fraxinus americana, Platanus acerifolia, Betula, and Populus. And the other occurs in late summer and autumn and is caused by weed pollens, such as Artemisia, Amaranthus retroflexus, Humulus scandens, Kochia scoparia and Chenopodium glaucum. However, sensitization to grass pollen has never been assessed. In this multicenter study, to determine the impact of pollen exposure in terms of duration and concentration, we analyzed the $\operatorname{IgE}$ sensitization profiles to $P$. pratense allergens in patients from northern China.

\section{Materials and Methods}

\section{Ethics Statement}

This study has been performed in accordance with the principles stated in the Declaration of Helsinki, and the study protocol was approved by the Research and Ethics Board of Peking Union Medical College Hospital (approval number: ZS-2342). Informed consent was signed by all patients or their parents before participation.

\section{Patients and Study Design}

This was a cross-sectional study on patients with seasonal ARC and/or asthma during the grass pollen season who visited the outpatient department for allergy in three cities in China. A total of 101 patients (62 men) were recruited from June to September 2020. Among them, 51 were from greater Beijing (BJ) including Beijing city and its surrounding area, 37 were from Shenmu city (SM) in Shanxi province, and 13 were from Shizuishan city (SZS) in Ningxia Hui Autonomous Region. The patients ranged in age from 1 to 64 years, with a median age of 10 years. According to the standard protocol, all patients underwent a comprehensive diagnostic workup including questionnaire completion, physical examination and skin prick test (SPT). Inclusion criteria were self-reported symptoms of ARC and/or asthma during the grass pollen season for at least 2 years, and positive SPT results to timothy grass. Exclusion criteria were ongoing or complete allergen-specific immunotherapy with pollen, and/or the presence of perennial symptoms of ARC or asthma. The study design is illustrated in Figure 1.

\section{Pollen Concentration}

We retrospectively analyzed the pollen data in BJ, SM and SZS to focus on two geographic areas: northern and northwest China. Daily pollen monitoring was performed from 01 January to 31 December 2013 in the three cities and from May to October 2020 in SM and March to October 2020 in SZS, by a gravitational method using a modified Durham pollen sampler described by $\mathrm{Ye}^{19}$ and white petrolatum as an adhesive. The pollen samplers for BJ, SZS and SM were set on the top of buildings located in Peking Union Medical College Hospital, The No.1 People's Hospital of Shizuishan and Shenmu Hospital, respectively, at a height of 16-18 m above the ground and with good ventilation. Each slide was placed daily at 08:00 am and collected 24 hours later. The daily slides were attained, identified and counted by a trained technician. The daily pollen concentrations were reported as grains $/ \mathrm{m}^{3}$. For ease of description, we used monthly and annual pollen concentrations for this study, presented as grains $/ \mathrm{m}^{3} /$ month and grains $/ \mathrm{m}^{3} /$ year 


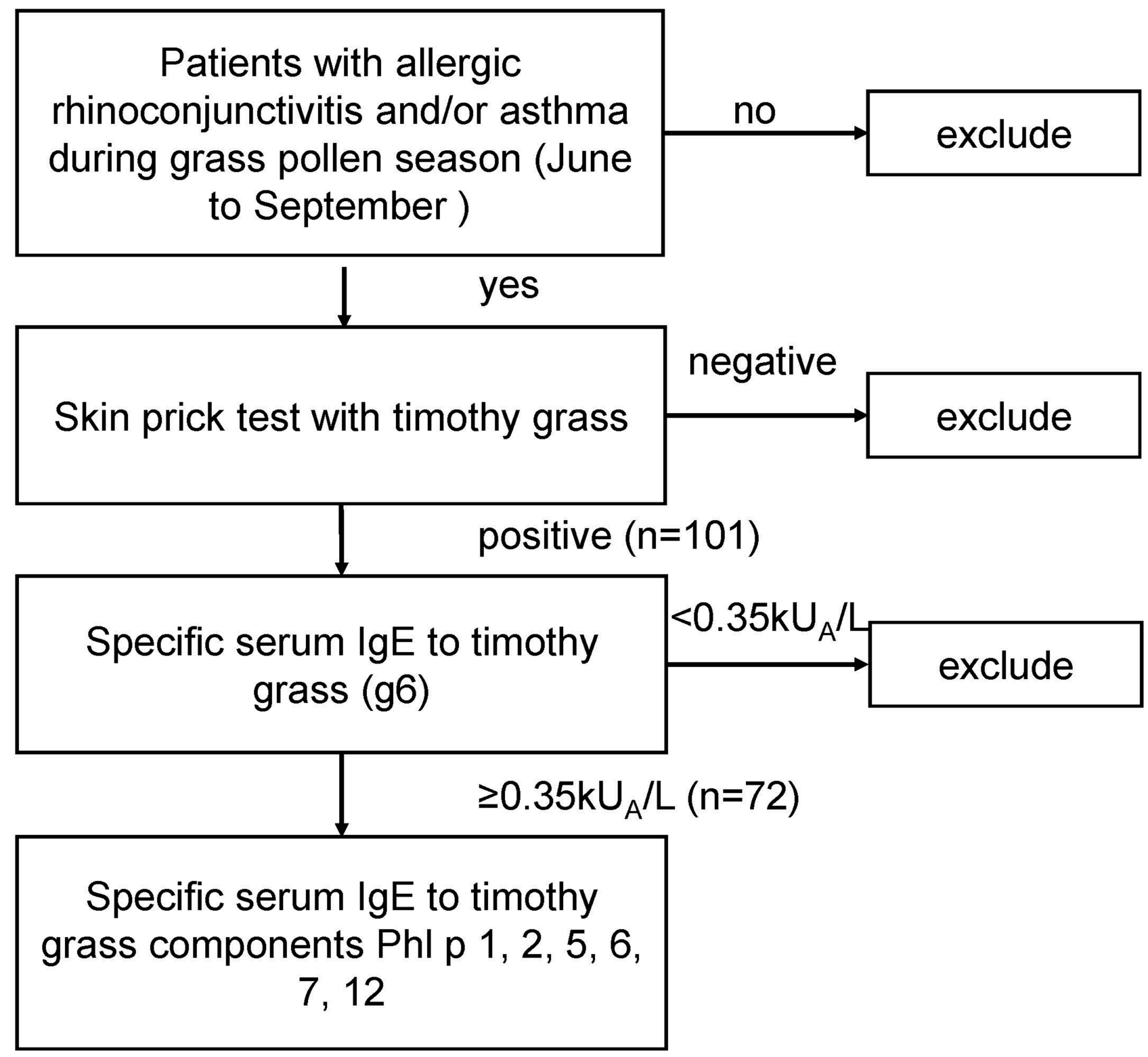

Figure I Study design.

respectively. Thirty-eight pollen species from weeds, trees and grasses were counted. The duration of each pollen season was calculated based on the EAACI definition. ${ }^{20}$ The definition of the birch pollen season was used to calculate the pollen season for trees and weeds pollen.

\section{Skin Prick Test}

An SPT with timothy grass extract (Soluprick SQ Phleum pratense, ALK, Denmark) was performed in all patients. Common allergic pollen including Salix caprea, Sabina chinensis, Fraxinus americana, Platanus acerifolia, Betula, Populus, Artemisia, Amaranthus retroflexus,
Humulus scandens and Chenopodium glaucum was also evaluated by SPT. A positive reaction was defined as mean wheal diameter $\geq 3 \mathrm{~mm}$.

\section{Serum Specific lgE Measurement}

Serum-specific IgE (sIgE) against timothy grass (g6), its components Phl p 1 (g205), Phl p 2 (g206), Phl p 5 (g215), Phl p 6 (g209), Phl p 7 (g210), and Phl p 12 (g212), and mugwort (w6) were tested by the ImmunoCAP allergen system (Phadia 1000, ThermoFisher Scientific, Uppsala, Sweden). A positive value was defined as detectable $\operatorname{sgE} \geq$ $0.35 \mathrm{kU}_{\mathrm{A}} / \mathrm{L}$. 


\section{Statistical Analysis}

Statistical analyses were performed using SPSS 20.0 software (SPSS Inc., Chicago, IL, USA). Differences in the prevalence of timothy grass components in the three areas were analyzed by the Fisher test. The Spearman correlation test was used to analyze the potential correlations between different components of grass pollen and cosensitization profiles. $P$ values of $p<0.05$ were considered to indicate statistical significance.

\section{Results}

\section{Pollen Data}

The daily and monthly pollen concentrations in BJ, SM and SZS are shown in Figure 2A and B. Two predominant pollen seasons were observed. One season was caused by tree pollens from March to May, with an annual pollen index (API) of 9614 grains $/ \mathrm{m}^{3} /$ year in BJ, 4018 grains $/ \mathrm{m}^{3} /$ year in $\mathrm{SM}$ and 3133 grains $/ \mathrm{m}^{3} /$ year in SZS. The other season occurred from July to September or even October and was caused by Artemisia (mugwort) and other weed pollens, such as
Humulus, Chenopodium, and Amaranthaceae. The API of the weed pollen season was 19,400 grains $/ \mathrm{m}^{3} /$ year in BJ, 23,262 grains $/ \mathrm{m}^{3} /$ year in SM and 18,959 grains $/ \mathrm{m}^{3} /$ year in SZS (Figure 2C). In terms of individual species, mugwort had the highest annual sums of recorded counts (Figure 2C). Specifically, the API of mugwort was 10,228 grains $/ \mathrm{m}^{3} /$ year in $\mathrm{BJ}, 22,230$ grains $/ \mathrm{m}^{3} /$ year in SM and 7354 grains $/ \mathrm{m}^{3} /$ year in SZS.

The API of Poaceae pollen was 708 grains $/ \mathrm{m}^{3} /$ year in BJ with a pollen season from June to September, 798 grains $/ \mathrm{m}^{3} /$ year in SM with a pollen season from May to September and 420 grains $/ \mathrm{m}^{3} /$ year in SZS with the pollen season from July to August.

\section{Demographic and Clinical Characteristics of the Patients}

Based on the inclusion criteria, 101 patients were recruited (62 men, 39 women) with a median age of 10 years (rang, 164 years). Sixty-three (62\%) patients were children aged $\leq 13$ years. The age distribution of the patients is illustrated in
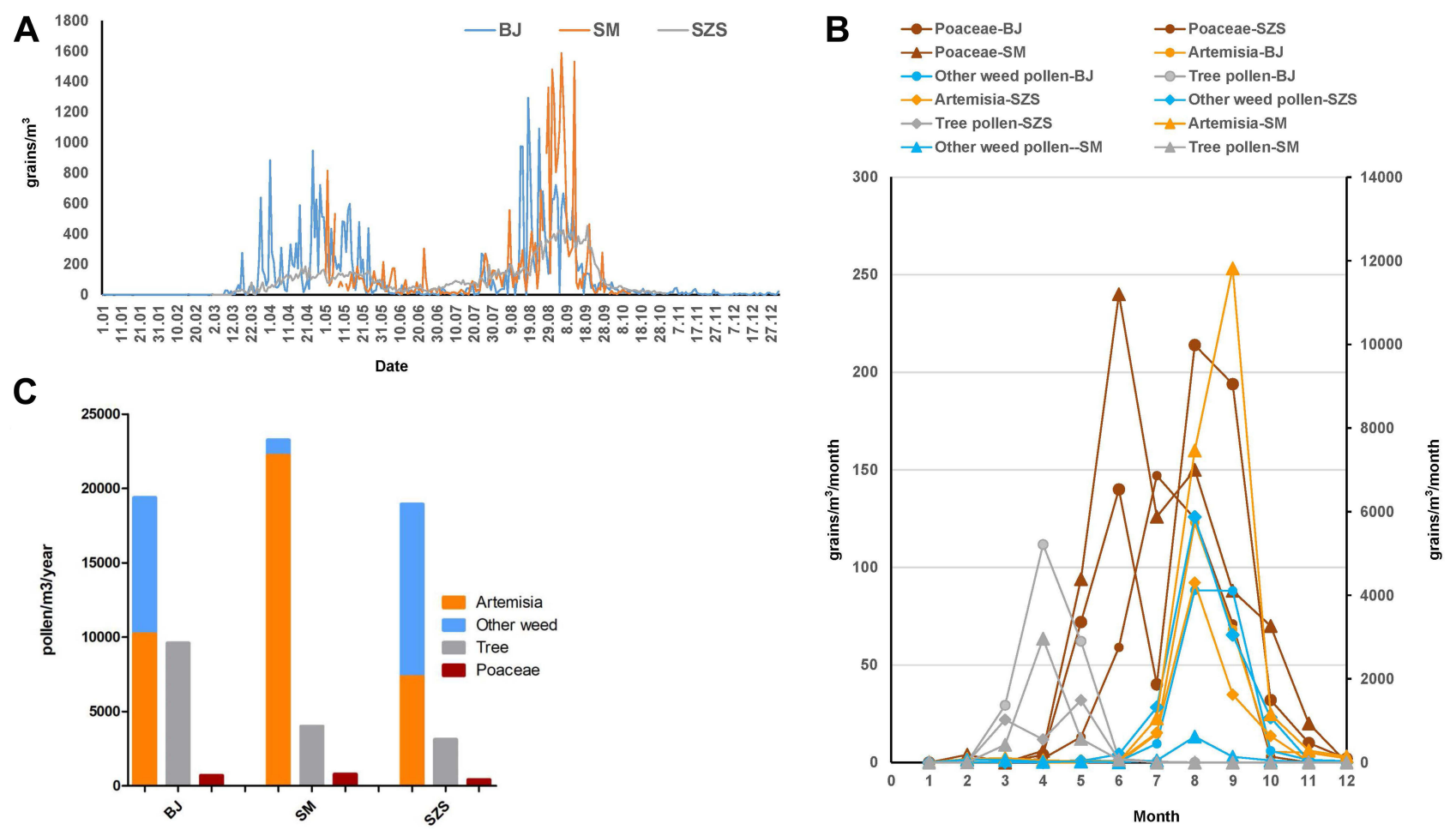

Figure 2 Pollen concentration in three areas. Pollen monitoring was performed by a gravitational method using a modified Durham pollen sampler described by Ye. ${ }^{19}$ Notes: (A) Daily pollen concentration in BJ (data collected from 0 I January to 3I December, 20I3), SM (data collected from 0 I May to I2 October, 2020) and SZS (data collected from 0 I March to $3 \mathrm{I}$ October, 2020). (B) Monthly pollen concentration in BJ, SM and SZS. Pollen monitoring was performed from $0 \mathrm{I}$ January to $3 \mathrm{I}$ December 2013. The concentration of Poaceae pollen refers to the left vertical axis and the concentration of Artemisia, other weed and tree pollens refer to the right vertical axis. The season of Poaceae pollen was from June to September or even October, and overlapped with weed pollen. The Poaceae pollen concentration is much lower than the other three types of pollen. (C) The annual pollen index (API) of Poaceae, Artemisia, other weed and tree pollens. Artemisia is the major type in weed pollens. Compared to the other three types pollen, the API of Poaceae pollen is much lower. 


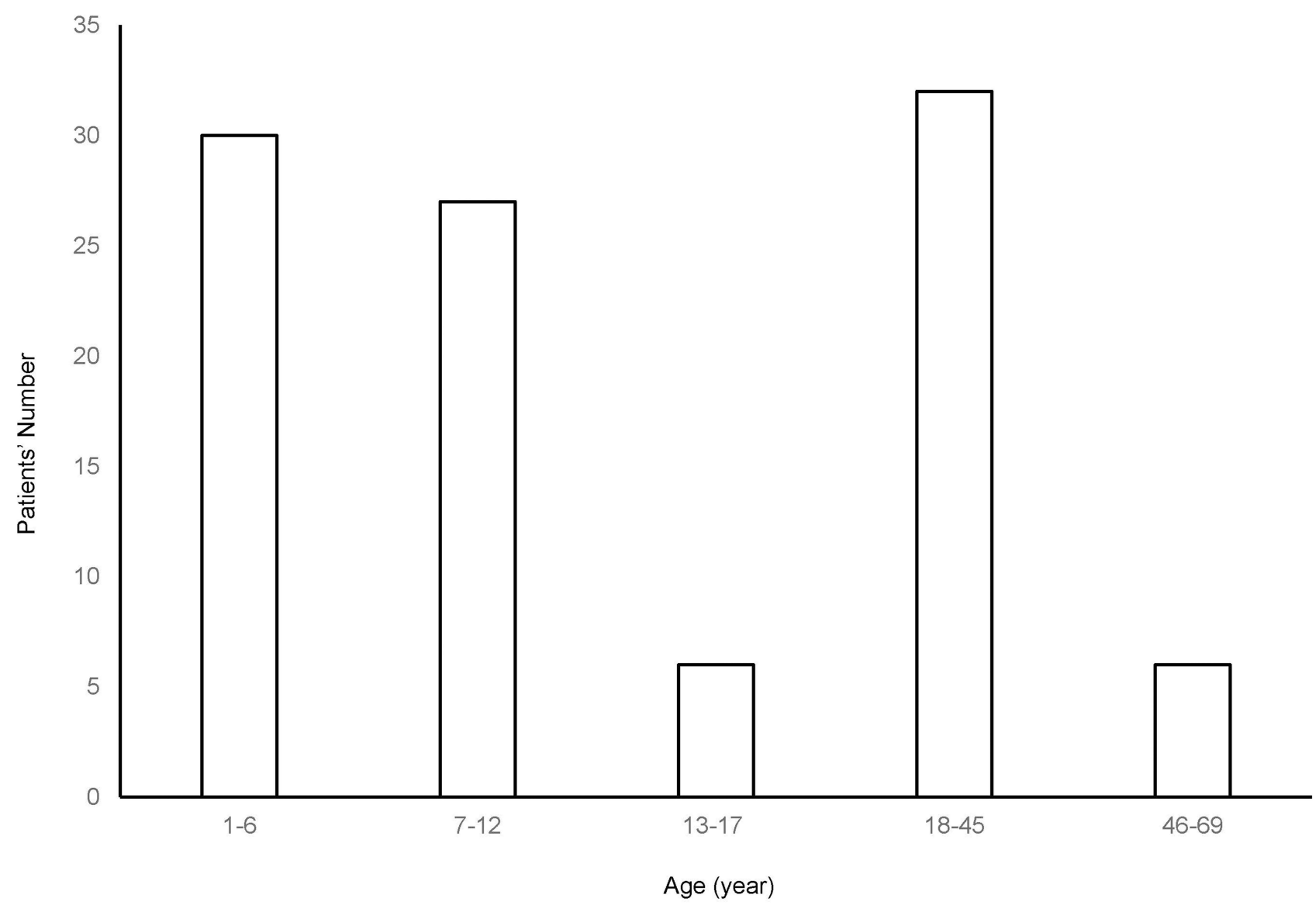

Figure 3 The age distribution of patients.

Notes: $29 \%$ of patients were aged I-6 years, $26 \%$ aged $7-12$ years and $31 \%$ aged $18-45$ years.

Figure 3. All 101 of patients presented with ARC, and 73 patients $(72 \%)$ had ARC combined with asthma.

\section{IgE Reactivity Profiles to Timothy Grass and Its Components}

Timothy grass sIgE was detected in 73 (72\%) of 101 patients with positive SPT results to timothy grass. Timothy grass allergen components were further assessed in these 73 patients. Phl p 12 was the most frequently recognized allergen with a prevalence of $45 \%(\mathrm{n}=33 / 73)$, followed by $\mathrm{Phl} \mathrm{p}$ 1 (22\%; n=16/73), Phl p 5 (14\%, n=10/73), Phl p 6 (8\%, $\mathrm{n}=6 / 73)$ and $\mathrm{Phl} \mathrm{p} 7(3 \%, \mathrm{n}=2 / 73)$. No patients were positive for $\mathrm{Phl} \mathrm{p} 2$. The positive rates for each component are summarized in Table 1. Ten patterns of sIgE against the timothy grass components were observed (Table 2).

The prevalence of sensitization to the components was quite different among the three areas. The frequency of sIgE to Phl p 1, Phl p 5 and Phl p 6 in SM were 63\%, 63\% and $38 \%$, respectively, and much higher than the corresponding frequency in $\mathrm{BJ}(4 \%, 0 \%$ and $0 \% ; \mathrm{p}<0.05)$ and SZS $(25 \%, 0 \%$ and $0 \% ; \mathrm{p}<0.05)$. The prevalence of sIgE to Phl p 12 in BJ (49\%) and SZS (75\%) was significantly higher than that in SM $(19 \% ; \mathrm{p}<0.05)$.

\section{Co-Sensitization Profiles}

On the basis of their reactivity to common weed and tree pollens, timothy grass-sensitized patients were assigned to timothy grass monosensitization and polysensitization groups. In the 73 patients with both positive SPT results and $\operatorname{sIgE}$ to timothy grass, only $5(7 \%)$ were monosensitized and 68 (93\%) were polysensitized to other pollen. Meanwhile, in the 28 patients with positive SPT results but no sIgE to timothy grass, 10 (36\%) had no detectable sIgE to the common pollen allergens. For the polysensitized patients, $65(89 \%)$ patients were positive to weed pollen and $63(86 \%)$ positive to mugwort pollen, while $65(89 \%)$ were positive to tree pollen and $45(62 \%)$ were sensitized to birch pollen. 
Table I Prevalence of Phleum pratense Pollen Components

\begin{tabular}{|c|c|c|c|c|c|c|c|c|}
\hline & \multicolumn{8}{|c|}{ Positive Rate of Specific IgE to Each Component of Phleum pratense in Different Areas } \\
\hline & $\begin{array}{c}\text { Total } \\
(n=73)\end{array}$ & Prevalence & $\begin{array}{l}\text { Beijing } \\
(n=49)\end{array}$ & Prevalence & $\begin{array}{l}\text { Shenmu } \\
(n=16)\end{array}$ & Prevalence & $\begin{array}{c}\text { Shizuishan } \\
\quad(n=13)\end{array}$ & Prevalence \\
\hline $\mathrm{Phl} \mathrm{p} \mathrm{I}$ & 16 & $22 \%$ & 4 & $8 \%$ & 10 & $63 \%$ & 2 & $25 \%$ \\
\hline $\mathrm{Phl} \mathrm{p} 2$ & 0 & $0 \%$ & 0 & $0 \%$ & 0 & $0 \%$ & 0 & $0 \%$ \\
\hline $\mathrm{Phl}$ p 5 & 10 & $14 \%$ & 0 & $0 \%$ & 10 & $63 \%$ & 0 & $0 \%$ \\
\hline $\mathrm{Phl}$ p 6 & 6 & $8 \%$ & 0 & $0 \%$ & 6 & $38 \%$ & 0 & $0 \%$ \\
\hline Phl p 7 & 2 & $3 \%$ & 2 & $4 \%$ & 0 & $0 \%$ & 0 & $0 \%$ \\
\hline $\mathrm{Phl} p \mathrm{I} 2$ & 33 & $45 \%$ & 24 & $49 \%$ & 3 & $19 \%$ & 6 & $75 \%$ \\
\hline
\end{tabular}

Table 2 Number of Patients in Relation to IgE Sensitization Pattern to Each Component of Phleum pratense

\begin{tabular}{|l|c|c|c|c|c|c|}
\hline Phl & Phl & Phl & Phl & Phl & Phl & Number \\
P I & P 2 & P 5 & P 6 & P 7 & P I 2 & \\
\hline- & - & - & - & - & + & 28 \\
- & - & - & - & - & - & 24 \\
+ & - & - & - & - & + & 3 \\
- & - & + & + & - & - & 4 \\
+ & - & - & - & - & - & 7 \\
+ & - & + & + & - & - & 3 \\
+ & - & + & - & - & - & 3 \\
- & - & - & + & - & + & $\mathrm{I}$ \\
- & - & - & - & + & - & $\mathrm{I}$ \\
- & - & - & - & + & + & $\mathrm{I}$ \\
\hline
\end{tabular}

In the timothy grass polysensitization group, the correlations between SIgE to timothy grass components and cosensitization profiles to weed or tree pollen were analyzed. The presence of Phl p 1, Phl p 5 and/or Phl p 6 was considered a genuine grass allergy. Significant negative correlations between genuine grass allergy and sensitization to weed pollen $(\mathrm{R}=-0.356, \mathrm{p}<0.05)$ or tree pollen $(\mathrm{R}=-0.337, \mathrm{p}<0.05)$ were found. Phl p 12 had a weak positive association with sensitization to weed pollen $(\mathrm{R}=$ 0.267, $\mathrm{p}<0.05)$ or tree pollen $(\mathrm{R}=0.271, \mathrm{p}<0.05)$.

\section{Discussion}

Grasses are wildly grown in northern China for multiple purposes, such as cattle feeding, or reinforcement and improvement of soil and city lawns. Leymus chinensis, Dactylis glomerata and Bromus inermis Leyss belonging to the Pooideae subfamily are the most commonly grown species. In the present study, we collected pollen data for three cities located in three geographic areas in northern China. The results showed that the pollen season of Pooideae species lasted for 5-6 months, from May to September or even
October. The season started at the end of the tree pollen season, but overlapped with the weed pollen season in August and September. June was relatively pure for the grass pollen season with no overlap for the tree and weed pollen seasons. The pollen season duration was similar among the three areas. Concerning the pollen quantities, mugwort pollen was predominant in August and September. Specifically, mugwort pollen accounted for $79 \%$ of the annual sum of pollen counts in SM, $34 \%$ in BJ and 33\% in SZS. Pollen from other weed species, mainly Chenopodium, Humulus hop, and Amaranthaceae, were also important allergens in BJ (31\% of the annual sum of pollen counts) and SZS (52\%). Compared with these major pollens, the API of grass was very low, accounting for $2-3 \%$ of the annual sum of pollen counts.

Based on the large degree of cross-reactivity between timothy grass and other grass species, ${ }^{9}$ we used timothy grass as representative grass species. Phl p 1 is the most prevalent component in patients with grass allergy and is a major allergen in grass pollen. $\mathrm{Phl} p 5$ and $\mathrm{Phl} \mathrm{p} 6$ are other major allergens in grass pollen with prevalence of more than $50 \% .^{21} \mathrm{Phl} \mathrm{p} 1$ is present in all types of grass pollen, while Phl p 5 and Phl p 6 are specific for Pooideae pollen. Thus, positive results to $\mathrm{Phl} p 1$ and $\mathrm{Phl} p 5$ are considered to be genuine grass allergy. In Europe, more than $90 \%$ of grass allergy patients were sensitized to $\mathrm{Phl}$ p 1, of whom $20 \%$ were monosensitized to $\mathrm{Phl} p 1^{21-23}$ Following Phl p 1, the prevalence of sensitization to $\mathrm{Phl}$ p 2, Phl p 5 and $\mathrm{Phl}$ p 6 was around 50\% for each component. In the present study, the findings for patients in China were quite different from those for patients in Europe. In China, only $22 \%$ of patients were sensitized to Phl p 1, of whom $43 \%(n=7 / 16)$ were monosensitized to $\mathrm{Phl} \mathrm{p} 1$. The positive rate of sensitization to $\mathrm{Phl} \mathrm{p} 2(0 \%)$, $\mathrm{Phl}$ p 5 (14\%) and Phl p 6 (8\%) in China were significantly lower than those in Europe. A study on grass sensitization in southern China showed similar, low prevalences of 
sensitization to $\mathrm{Phl} \mathrm{p} 1$ (22\% vs $17 \%)$, Phl p 5 (14\% vs $8 \%)$ and Phl p 6 ( $8 \%$ vs $8 \%$ ), but found no patients who were monosensitized to Phl p 1. ${ }^{24}$ The difference in sensitization patterns to grass pollen components could be essential when component-resolved immunotherapy is considered for patients with grass allergy. BM32 is a novel recombinant vaccine for grass pollen allergy that consists of hypoallergenic peptides from $\mathrm{Phl} \mathrm{p} \mathrm{1,} \mathrm{Phl} \mathrm{p} \mathrm{2,}$ $\mathrm{Phl} \mathrm{p} 5$ and $\mathrm{Phl} \mathrm{p} 6{ }^{25}$ The vaccine was designed on the basis of allergenic relevance and the prevalence of sensitization to grass components in the population. ${ }^{26}$ However, the sensitization patterns were highly heterogeneous and showed large variation among different geographic areas. In our study population, no patients had sIgE to Phl $\mathrm{p} 2$. Therefore, component-based immunotherapy vaccines should consider the heterogeneity and local characteristics of sensitization patterns for tailoring to patients.

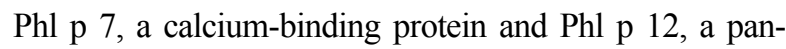
allergen profilin, are the main cross-reactive components between grass, tree and weed pollens. The positive rate of sensitization to $\mathrm{Phl} \mathrm{p} 7$ and Phl p 12 in Europe were lower than those to the major allergens mentioned above, varying from $2 \%$ to $5 \%$ for $\mathrm{Phl} \mathrm{p} 7$ and 2-25\% for Phl p 12. ${ }^{21,27}$ Similarly, in southern China, sensitization to $\mathrm{Phl} \mathrm{p} 7$ and $\mathrm{Phl}$ p 12 was detected in $8 \%$ of the patients with positive sIgE to timothy grass allergens. ${ }^{24}$ The prevalence of sensitization to $\mathrm{Phl} p 7$ was also low in the present study. In contrast to previous reports, we found that approximately one-half of the patients in this study were positive for sensitization to Phl p 12 and $85 \%$ $(n=28 / 33)$ were monosensitized to Phl p 12. There was a positive correlation between $\mathrm{Phl} \mathrm{p} 12$ sensitization and weed/tree pollen sensitization. It is known that the prevalence of sensitization to pan-allergens is higher in patients from areas where pollen seasons overlap, especially when major allergens appear during the same period. Based on the pollen data, all three study areas had extensive exposure to weed pollen, particularly mugwort pollen. The API for weeds was approximately 30-40 times higher than that for grasses and the pollen seasons of weeds and grasses overlapped. Based on the sensitization data, $93 \%$ of timothy grass sensitized patients were cosensitized to weed and/or tree pollen, and the majority of them had positive results to mugwort and/or birch pollen. All patients with sIgE to $\mathrm{Phl} p 12$ had positive results to mugwort pollen. It has been demonstrated that $\mathrm{Phl} p 12 \mathrm{sIgE}$ detection is positively correlated with Art v 4, a profilin allergen in mugwort pollen. ${ }^{28}$ Thus, the high rate of sensitization to Phl $\mathrm{p} 12$ was considered to result from cross-reactivity with weed/tree pollen (especially mugwort) allergy. It was shown that crossreactive carbohydrate determinants (CCDs) have a low influence on Phl p 12 sensitization. ${ }^{28}$ In contrast, genuine allergy to timothy grass (positive results to $\mathrm{Phl} \mathrm{p} \mathrm{1,} \mathrm{Phl} \mathrm{p} \mathrm{5,} \mathrm{and/or} \mathrm{Phl}$ p 6) was negatively correlated with weed or tree pollen sensitization.

There were some limitations to the present study. First, because grass pollen components have not been registered for clinical use in China and it is difficult to import them during the current COVID-19 pandemic, Phl p 4 was not detected. $\mathrm{Phl}$ p4 contains CCDs and shows broad cross-reactivity among grass pollens. Second, the pollen data is not comprehensive and satisfactory. Based on various reasons, integrated daily pollen concentration from 2020 in three study areas are lacking. To describe the API of different pollen species and the pollen season, pollen concentration from 2013 was used.

\section{Conclusions}

In summary, this study analyzed the sensitization profiles to timothy grass pollen in northern China. On the basis of the pollen concentration and sensitization patterns, timothy grass pollen was a minor allergic pollen in northern China, and approximately one-half of the sensitized patients were induced by weed and/or tree pollen allergy.

\section{Abbreviations}

ARC, allergic rhinoconjunctivitis; AIT, allergen-specific immunotherapy; API, annual pollen index; BJ, Beijing; CCD, cross-reactive carbohydrate determinants; SPT, skin prick test; SM, Shenmu; SZS, Shizuishan city; sIgE, specific IgE.

\section{Data Sharing Statement}

The data and materials are available from the corresponding authors based on reasonable requirement.

\section{Ethics Approval and Informed Consent}

This study has been performed in accordance with the principles stated in the Declaration of Helsinki, and the study protocol was approved by the Research and Ethics Board of Peking Union Medical College Hospital (approval number: ZS-2342).

\section{Consent for Publication}

All authors confirm that the details of the manuscript can be published. 


\section{Acknowledgments}

We thank Dr Xiaodong Liu, from the Department of Respiratory and Critical Care Medicine, Shenmu Hospital, Shanxi, People's Republic of China, for the acquisition of clinical data from Shenmu area.

\section{Author Contributions}

All authors made substantial contributions to conception and design, acquisition of data, or analysis and interpretation of data; took part in drafting the article or revising it critically for important intellectual content; agreed to submit to the current journal; gave final approval for the version to be published; and agreed to be accountable for all aspects of the work.

\section{Funding}

Natural Science Foundation of Beijing Municipality (No. 7212074).

\section{Disclosure}

The authors report no competing interests.

\section{References}

1. D'Amato G, Cecchi L, Bonini S, et al. Allergenic pollen and pollen allergy in Europe. Allergy. 2007;62:976-990. doi:10.1111/j.13989995.2007.01393.x

2. CDC. Summary Health Statistics Tables for U.S. Adults: National Health Interview Survey; 2014.

3. Larsson O, Hellkvist L, Peterson-Westin U, Cardell LO. Novel strategies for the treatment of grass pollen-induced allergic rhinitis. Expert Opin Biol Ther. 2016;16:1143-1150. doi:10.1080/14712598.2016.1190829

4. Andersson K, Lidholm J. Characteristics and immunobiology of grass pollen allergens. Int Arch Allergy Immunol. 2003;130:87-107.

5. Ferreira F, Hawranek T, Gruber P, Wopfner N, Mari A. Allergic cross-reactivity: from gene to the clinic. Allergy. 2004;59:243-267. doi:10.1046/j.1398-9995.2003.00407.x

6. Hejl C, Wurtzen PA, Kleine-Tebbe J, Johansen N, Broge L, Ipsen H. Phleum pratense alone is sufficient for allergen-specific immunotherapy against allergy to pooideae grass pollens. Clin Exp Allergy. 2009;39:752-759. doi:10.1111/j.1365-2222.2008.03195.x

7. Johansen N, Weber RW, Ipsen H, Barber D, Broge L, Hejl C. Extensive IgE cross-reactivity towards the pooideae grasses substantiated for a large number of grass-pollen-sensitized subjects. Int Arch Allergy Immunol. 2009;150:325-334. doi:10.1159/000226233

8. Suphioglu C, Singh MB. Cloning, sequencing and expression in Escherichia coli of Pha a 1 and four isoforms of Pha a 5, the major allergens of canary grass pollen. Clin Exp Allergy. 1995;25:853-865. doi:10.1111/j.1365-2222.1995.tb00028.x

9. Laffer S, Valenta R, Vrtala S, et al. Complementary DNA cloning of the major allergen $\mathrm{Phl} \mathrm{p} \mathrm{I}$ from timothy grass (Phleum pratense); recombinant $\mathrm{Phl} \mathrm{p} \mathrm{I}$ inhibits IgE binding to group I allergens from eight different grass species. $J$ Allergy Clin Immunol. 1994;94:689-698. doi:10.1016/0091-6749(94)90176-7

10. Campbell BC, Gilding EK, Timbrell V, et al. Total transcriptome, proteome, and allergome of Johnson grass pollen, which is important for allergic rhinitis in subtropical regions. J Allergy Clin Immunol. 2015;135:133-142. doi:10.1016/j.jaci.2014.06.034
11. Chew FT, Lim SH, Shang HS, et al. Evaluation of the allergenicity of tropical pollen and airborne spores in Singapore. Allergy. 2000;55:340-347. doi:10.1034/j.1398-9995.2000.00308.x

12. Sibanda EN. Inhalant allergies in Zimbabwe: a common problem. Int Arch Allergy Immunol. 2003;130:2-9. doi:10.1159/000068377

13. Boral D, Chatterjee S, Bhattacharya $\mathrm{K}$. The occurrence and allergising potential of airborne pollen in West Bengal, India. Ann Agric Environ Med. 2004;11:45-52.

14. Cheng S, Yu Y, Ruan B. Species and distribution of airborne pollen plants in major cities of China. Chin J Allergy Clin Immunol. 2015:136-141. Available from: http://en.cnki.com.cn/Article_en/ CJFDTOTAL-OZHL201502013.htm. Accessed November 15, 2021. Chinese.

15. Li Q, Jiang S, Li X, Zhu X, Wei Q. Seasonal and geographical dispersal regularity of airborne pollens in China. Med $J$ Chin People Liberation Army. 2017;42:951-955.

16. Wang Y, Xiao X, Zhan Z, et al. Airborne pollens in Zhongshan city. Chin J Allergy Clin Immunol. 2012;6:261-265.

17. Ouyang YH, Zhang DS, Fan EZ, Li Y, Zhang L. Correlation between symptoms of pollen allergic rhinitis and pollen grain spreading in summer and autumn. Chin J Otorhinolaryngology Head Neck Surg. 2012;47:623-627.

18. Hu W, Zhu L, Xie L, et al. Correlation between the visiting rate of patients with allergic rhinitis and airborne pollen concentrations in Beijing in recent 3 years. Chin J Otorhinolaryngology Head Neck Surg. 2017;52:31-36.

19. Ye S, Zhang J, Qiao B, Lu Y. Airborne and Allergenic Pollen Grains in China. Vol. 1. Beijing: Science Press; 1998.

20. Pfaar O, Bastl K, Berger U, et al. Defining pollen exposure times for clinical trials of allergen immunotherapy for pollen-induced rhinoconjunctivitis - an EAACI position paper. Allergy. 2017;72:713-722. doi:10.1111/all.13092

21. Tripodi S, Frediani T, Lucarelli S, et al. Molecular profiles of IgE to phleum pratense in children with grass pollen allergy: implications for specific immunotherapy. J Allergy Clin Immunol. 2012;129 (3):834-839.e8. doi:10.1016/j.jaci.2011.10.045

22. De Amici M, Alesina R, Moratti R, Ciprandi G. Component-resolved diagnosis for phleum allergy: the role of recombinants. $J$ Asthma. 2010;47:750-753. doi:10.3109/02770903.2010.489247

23. Laffer S, Spitzauer S, Susani M, et al. Comparison of recombinant timothy grass pollen allergens with natural extract for diagnosis of grass pollen allergy in different populations. J Allergy Clin Immunol. 1996;98:652-658. doi:10.1016/S0091-6749(96)70099-4

24. Luo W, Huang H, Zheng P, et al. Major grass pollen allergens and components detected in a southern Chinese cohort of patients with allergic rhinitis and/or asthma. Mol Immunol. 2016;78:105-112. doi:10.1016/j.molimm.2016.08.013

25. Eckl-Dorna J, Weber M, Stanek V, et al. Two years of treatment with the recombinant grass pollen allergy vaccine BM32 induces a continuously increasing allergen-specific $\operatorname{IgG}$ response. EBioMedicine. 2019;50:421-432. doi:10.1016/j.ebiom.2019.11.006

26. Gangl K, Niederberger V, Valenta R. Multiple grass mixes as opposed to single grasses for allergen immunotherapy in allergic rhinitis. Clin Exp Allergy. 2013;43:1202-1216. doi:10.1111/cea.12128

27. Ciprandi G, Scala E, Ariano R. molecular pattern across Italy. Eur Ann Allergy Clin Immunol. 2017;49:176-180. doi:10.23822/ EurAnnACI.1764-1489.01

28. Liao C, Liang $\mathrm{C}, \mathrm{Hu} \mathrm{H}$, et al. Major pollen allergen components and CCD detection in Bermuda grass sensitized patients in Guangzhou, China. J Asthma Allergy. 2020;13:615-623. doi:10.2147/JAA. S277704 


\section{Publish your work in this journal}

The Journal of Asthma and Allergy is an international, peer-reviewed open-access journal publishing original research, reports, editorials and commentaries on the following topics: Asthma; Pulmonary physiology; Asthma related clinical health; Clinical immunology and the immunological basis of disease; Pharmacological interventions and new therapies. The manuscript management system is completely online and includes a very quick and fair peer-review system, which is all easy to use. Visit http://www.dovepress.com/testimonials.php to read real quotes from published authors.

Submit your manuscript here: https://www.dovepress.com/journal-of-asthma-and-allergy-journal 